\title{
Health Impacts and Economic Costs of Air Pollution in the Metropolitan Area of Skopje
}

\author{
Gerardo Sanchez Martinez ${ }^{1,2}$ (D), Joseph V. Spadaro ${ }^{3, *}$, Dimitris Chapizanis ${ }^{4}$, \\ Vladimir Kendrovski ${ }^{2}$ (D), Mihail Kochubovski ${ }^{5}$ and Pierpaolo Mudu ${ }^{2, *}$ \\ 1 The UNEP-DTU Partnership, Department of Management Engineering, Technical University of Denmark, \\ UN City, Marmorvej 51, 2100 Copenhagen Ø, Denmark; gsama@dtu.dk \\ 2 WHO European Centre for Environment and Health, Platz der Vereinten Nationen 1, 53113 Bonn, Germany; \\ kendrovskiv@who.int \\ 3 SERC, Hillsborough, NJ 08844, USA \\ 4 Environmental Engineering Laboratory, Department of Chemical Engineering, Aristotle University of \\ Thessaloniki, 54124 Thessaloniki, Greece; dimitris@eng.auth.gr \\ 5 Institute of Public Health, 50 Divizija 6, 1000 Skopje, The former Yugoslav Republic of Macedonia; \\ kocubov58@gmail.com \\ * Correspondence: joseph.spadaro@aol.com (J.V.S.); mudup@who.int (P.M.); Tel.: +49-228-8150-400 (P.M.)
}

Received: 26 January 2018; Accepted: 27 March 2018; Published: 29 March 2018

\begin{abstract}
Background: Urban outdoor air pollution, especially particulate matter, remains a major environmental health problem in Skopje, the capital of the former Yugoslav Republic of Macedonia. Despite the documented high levels of pollution in the city, the published evidence on its health impacts is as yet scarce. Methods: we obtained, cleaned, and validated Particulate Matter (PM) concentration data from five air quality monitoring stations in the Skopje metropolitan area, applied relevant concentration-response functions, and evaluated health impacts against two theoretical policy scenarios. We then calculated the burden of disease attributable to PM and calculated the societal cost due to attributable mortality. Results: In 2012, long-term exposure to $\mathrm{PM}_{2.5}\left(49.2 \mu \mathrm{g} / \mathrm{m}^{3}\right)$ caused an estimated 1199 premature deaths (CI95\% 821-1519). The social cost of the predicted premature mortality in 2012 due to air pollution was estimated at between 570 and 1470 million euros. Moreover, $\mathrm{PM}_{2.5}$ was also estimated to be responsible for 547 hospital admissions (CI95\% 104-977) from cardiovascular diseases, and 937 admissions (C195\% 937-1869) for respiratory disease that year. Reducing $\mathrm{PM}_{2.5}$ levels to the EU limit $\left(25 \mu \mathrm{g} / \mathrm{m}^{3}\right)$ could have averted an estimated $45 \%$ of PM-attributable mortality, while achieving the WHO Air Quality Guidelines $\left(10 \mu \mathrm{g} / \mathrm{m}^{3}\right)$ could have averted an estimated $77 \%$ of PM-attributable mortality. Both scenarios would also attain significant reductions in attributable respiratory and cardiovascular hospital admissions. Conclusions: Besides its health impacts in terms of increased premature mortality and hospitalizations, air pollution entails significant economic costs to the population of Skopje. Reductions in $\mathrm{PM}_{2.5}$ concentrations could provide substantial health and economic gains to the city.
\end{abstract}

Keywords: air pollution; Skopje; the former Yugoslav Republic of Macedonia; particulate matter; economic evaluation; burden of disease

\section{Introduction}

Air pollution causes significant health burdens worldwide [1]. Globally, the World Health Organization (WHO) estimates that 3 million premature deaths annually were attributable to ambient air pollution in 2012 [2]. About 480,000 of those premature deaths are estimated to have occurred in the WHO European Region, comprising 53 countries. The health effects of inhalable particulate matter 
(PM) are well documented. There is no evidence of a safe level of PM concentration [3], and more than $80 \%$ of the population in the WHO European Region lives in cities with levels of PM exceeding WHO Air Quality Guidelines [4]. In 2005, pollution from PM was estimated to reduce the typical life expectancy of an individual in the region by almost 9 months [4].

The former Yugoslav Republic of Macedonia (hereon MKD), and particularly Skopje-the capital and largest city of the country-have long suffered from poor air quality. In the WHO European region, MKD $\left(37 \mu \mathrm{g} / \mathrm{m}^{3}\right)$ ranks third after Bosnia and Herzegovina $\left(42 \mu \mathrm{g} / \mathrm{m}^{3}\right)$ and Tajikistan $\left(41 \mu \mathrm{g} / \mathrm{m}^{3}\right)$ for the annual population-weighted modelled urban and rural median concentration of $\mathrm{PM}_{2.5}$ [2]. In the 20th century Skopje has experienced rapid urbanization, growth of industrial activities, and reconstruction after the 1963 earthquake. With a comparatively large number of industrial point sources and higher traffic flows than other cities in the country, the Skopje agglomeration has historically experienced frequent episodes of heavy pollution $[5,6]$. During dry periods, the combination of mineral dust and emissions from residential heating, the transport sector, and industrial activities within the city increase the concentrations of inhalable particles $[7,8]$.

Topography and meteorological conditions contribute to poor air quality in Skopje [9]. The city is situated in a valley and the river Vardar crosses the city, causing high humidity, particularly during the winter [10]. Additionally, heating facilities increase air pollution in winter [11]. An atmospheric anticyclone contributes to atmospheric temperature inversion, worsening ambient pollution levels, including particles with an aerodynamic diameter of less than 10 micrometres $\left(\mathrm{PM}_{10}\right)$ and increasing hospital admissions among patients with cardiovascular diseases. An increase of $10 \mu \mathrm{g} / \mathrm{m}^{3}$ of $\mathrm{PM}_{10}$ above the currently maximum permitted values in the country $\left(50 \mu \mathrm{g} / \mathrm{m}^{3}\right.$ average over $\left.24 \mathrm{~h}\right)$ increased daily admissions of patients with cardiovascular diseases during 2010 in Skopje by an estimated $12 \%$ [6]. In addition to the human health burden incurred, the morbidity and premature mortality due to air pollution entail significant economic and social costs. These include, but are not limited to, the cost to society of premature deaths, the costs of healthcare for the sick due to poor air quality, and the loss of productivity associated to that sickness and/or caregiving for oneself or others [12]. Thus, significant cost savings can be added to the health gains attainable through air pollution abatement. In this paper, we estimate for the city of Skopje the current health burdens and mitigation benefits of pollution on the local population in terms of hospital admissions and premature mortality, and in terms of their associated costs. The WHO air quality guidelines [13] and European Union (EU) reference values for $\mathrm{PM}_{2.5}$ (Directive 2008/50/EC) are used as counterfactual policy scenarios for a reduction of air pollution.

\section{Materials and Methods}

\subsection{Selection of Pollutants and Data Processing}

$\mathrm{PM}_{2.5}$ (or $\mathrm{PM}_{10}$ ) is an indicator for estimating health impacts of ambient air pollution mixture. $\mathrm{PM}$ is highly correlated with other air pollutants, such as $\mathrm{NO}_{2}$ from transport. PM exposure has been linked to a variety of adverse health outcomes, including short-term symptoms, chronic morbidity effects, and premature mortality [14]. For data validation and processing, we used the methods developed by the World Health Organization and others for health impact assessment of air pollution $[15,16]$. These methods identified criteria to select the appropriate monitoring stations. For particulate matter, a monitoring station was considered eligible for the study only if daily data were available for more than $50 \%$ of the study period; the daily average value of concentration was considered valid only if more than $50 \%$ of hourly data were available.

In Skopje, five air quality monitoring stations were in operation at some point between 2005 and 2013, and these stations recorded $\mathrm{PM}_{10}$. Monitoring of $\mathrm{PM}_{2.5}$ was initiated in two of the stations in autumn 2011. Three stations have continuously monitored PM: Gazi Baba (urban background), Lisice (suburban industrial), and Rektorat (urban traffic) [17]. Overall, there was a high and significant correlation of measured $\mathrm{PM}_{10}$ for the 5 monitoring stations over the period 2012-2013. Average values 
measured by the monitoring stations for $\mathrm{PM}_{2.5}$ and $\mathrm{PM}_{10}$ were high (see Table 1), but availability of data were limited. The observed ratio $\mathrm{PM}_{2.5} / \mathrm{PM}_{10}$ was 0.610 for Centar and 0.609 for Karpos, both urban traffic monitoring stations.

Table 1. Data availability and mean values by pollutant and monitoring station in Skopje for three consecutive years.

\begin{tabular}{|c|c|c|c|c|c|c|c|c|c|c|c|c|c|c|c|}
\hline & \multicolumn{3}{|c|}{$\begin{array}{l}\text { Centar } \\
\text { (Traffic) }\end{array}$} & \multicolumn{3}{|c|}{$\begin{array}{c}\text { Gazi Baba } \\
\text { (Background) }\end{array}$} & \multicolumn{3}{|c|}{ Karpos (Traffic) } & \multicolumn{3}{|c|}{$\begin{array}{c}\text { Lisice } \\
\text { (Industrial) }\end{array}$} & \multicolumn{3}{|c|}{$\begin{array}{l}\text { Rektorat } \\
\text { (Traffic) }\end{array}$} \\
\hline $\mathrm{PM}_{2.5}$ (mean, $\mu \mathrm{g} / \mathrm{m}^{3}$ ) & \multicolumn{3}{|c|}{48.3} & \multicolumn{3}{|c|}{ n.a. } & \multicolumn{3}{|c|}{41.6} & \multicolumn{3}{|c|}{ n.a. } & \multicolumn{3}{|c|}{ n.a. } \\
\hline $\begin{array}{l}13 \text { December } 2011 \text { availability } \\
\text { (\% per year) }\end{array}$ & 28 & 91 & 85 & & n.a. & & 29 & 97 & 50 & & n.a. & & & n.a. & \\
\hline $\mathrm{PM}_{10}\left(\mathrm{mean}, \mu \mathrm{g} / \mathrm{m}^{3}\right)$ & & 79.2 & & & 84.4 & & & 68.3 & & & 108.6 & & & 71.7 & \\
\hline $\begin{array}{l}13 \text { December } 2011 \text { availability } \\
\text { (\% per year) }\end{array}$ & 28 & 91 & 90 & 3 & 58 & 58 & 29 & 97 & 91 & 86 & 92 & 98 & 21 & 96 & 99 \\
\hline
\end{tabular}

\subsection{Health Impact Assessment}

\subsubsection{Population Data}

The geographical area for the health impact assessment comprises the municipalities of Skopje in 2012 (not including Sopishte, physically segregated from the Skopje agglomeration). The target population considered is all residents exposed to the measured pollutants. This study focuses on health impacts of PM on the population of Skopje in 2012 and includes persons living in the surrounding municipalities of Skopje with the exception of Sopishte. According to official municipality statistics [18], the total population (not counting Sopishte) was 531,524 people, of which 260,216 (49\%) were men (157,973 over the age of 30 years) and 271,308 were women (173,501 older than 30 years). Population data by district (ten in total, again not counting Sopishte) and five-year age groups were obtained from the Macedonian statistical office [19]. Mortality data (all-cause, non-accidental, disaggregated by ICD10 chapters) were obtained for the analysis period (2011-2013) from the Macedonian State Statistical Office, and morbidity data were obtained for the same years from the Skopje Center of Public Health.

\subsubsection{Selection of Health Endpoints}

$\mathrm{PM}_{2.5}$ relative risks (RR) were used to estimate premature mortality in adults older than 30 years old from long-term exposure and to quantify health morbidity (Table 2).

Table 2. Selected air quality indicators and PM relative risks.

\begin{tabular}{|c|c|c|c|}
\hline $\begin{array}{c}\text { Health Endpoint (Specific } \\
\text { Population) }\end{array}$ & ICD10 Codes & Relative Risk (RR) & Source \\
\hline $\begin{array}{l}\text { All-cause mortality excl. accidents } \\
\text { (Adults } 30 \text { years and older) }\end{array}$ & A00-R99 & $\begin{array}{c}\text { For } 10 \mu \mathrm{g} / \mathrm{m}^{3} \text { increase in } \mathrm{PM}_{2.5} \mathrm{RR}= \\
1.062(95 \% \text { CI: } 1.040-1.083)\end{array}$ & [20] \\
\hline $\begin{array}{c}\text { Hospital admission for } \\
\text { cardiovascular diseases (all ages) }\end{array}$ & I00-I52 & $\begin{array}{c}\text { For } 10 \mu \mathrm{g} / \mathrm{m}^{3} \text { increases in } \mathrm{PM}_{2.5} \mathrm{RR}= \\
1.0091 \text { (95\% CI: } 1.0017-1.0166)\end{array}$ & $\begin{array}{l}\text { Air Pollution Epidemiology } \\
\text { Database-APED [14] }\end{array}$ \\
\hline $\begin{array}{l}\text { Hospital admissions for } \\
\text { respiratory diseases (all ages) }\end{array}$ & J00-J99 & $\begin{array}{c}\text { For } 10 \mu \mathrm{g} / \mathrm{m}^{3} \text { increases in } \mathrm{PM}_{2.5} \mathrm{RR}= \\
1.0190 \text { (95\% CI: } 1.0190-1.0402)\end{array}$ & $\begin{array}{l}\text { Air Pollution Epidemiology } \\
\text { Database-APED [14] }\end{array}$ \\
\hline
\end{tabular}

ICD10: International Classification of Diseases 10th revision.

Epidemiological calculations were carried out with WHO software AirQ+ [21,22]. The years of life lost (YLL) due to ambient air pollution were calculated using the life table calculator developed by Joseph Spadaro (obtainable upon request, see corresponding authors' details.) and recently integrated into AirQ+. YLL are calculated for each specific calendar year in relation to a given population that is projected until its extinction, in this case after 105 years. 
We computed $\mathrm{PM}_{2.5}$ impacts by calculating a population attributable fraction PAF, the proportion of incidence of specific health endpoints that is related to $\mathrm{PM}_{2.5}$ exposure:

$$
\mathrm{PAF}=1-1 / \mathrm{RR} \text { and } \mathrm{RR}=\mathrm{RRo}^{(\Delta \mathrm{C} / 10)}
$$

in which RRo are the relative risks of the health effects listed in Table 2 (e.g., for long-term mortality 1.062) and $\Delta C$ is the change in ambient air concentration relative to a counterfactual scenario in $\mu \mathrm{g} / \mathrm{m}^{3}$. The $\mathrm{PM}_{2.5}$ impacts are calculated as the product of the disease-specific PAF by the baseline mortality $\mathrm{BM}$ in the case of premature deaths (that is, premature deaths $=\mathrm{PAF} \times \mathrm{BM}$ ), or the disease incidence rate if assessing health morbidity. There is no safe $\mathrm{PM}_{2.5}$ threshold level below which no negative effects are expected. However, a target concentration is needed to determine the attributable impacts or potential benefits of reducing the air pollution by a specified amount.

\subsubsection{Pollution Mitigation Scenarios}

The following mitigation scenarios have been considered:

- Current situation-Annual average concentration of $\mathrm{PM}_{2.5}$ at $49.2 \mu \mathrm{g} / \mathrm{m}^{3}$

- Scenario 1: EU AQS-Annual average concentration of $\mathrm{PM}_{2.5}$ reduced to $25 \mu \mathrm{g} / \mathrm{m}^{3}$

- Scenario 2: WHO AQG-Annual average concentration of $\mathrm{PM}_{2.5}$ reduced to $10 \mu \mathrm{g} / \mathrm{m}^{3}$

Since $\mathrm{PM}_{2.5}$ data were incomplete, the "Current situation" estimate was calculated assuming a 0.61 conversion factor from $\mathrm{PM}_{10}$ to $\mathrm{PM}_{2.5}$. Scenario 1 is based on the air quality standards of the European Union (Directive 2008/50/EC) [23]. These seem like a sensible benchmark, since as an accession country, MKD would eventually be required to comply with EU standards. WHO air quality guidelines [13] recommend an annual average $\mathrm{PM}_{2.5}$ concentration equal to $10 \mu \mathrm{g} / \mathrm{m}^{3}$, which we chose for Scenario 2.

\subsection{Economic Evaluation of Premature Mortality}

One approach to value the burden of premature mortality is to multiply the predicted number of deaths by the "value of a statistical life" VSL. The VSL represents society's collective willingness to pay (WTP) for a small reduction in the annual mortality risk of death. The value of VSL is contextual: in this case, it refers to the value of preventing an anonymous premature death from exposure to air pollution. Various studies have derived VSL values in the European context [24-26]. A meta-analysis of VSL studies by [27] recommends for EU-27 a VSL of 3.6 million dollars (2005 prices), with an indicative range of 1.8 to 5.4 million dollars.

Ideally, national or regional studies should be used to value economic losses from exposure to ambient air pollution. In the absence of such studies, however, (2) may be used to transfer unit health costs (cost per case of illness or death) from a previous study to the policy location based on the "benefit-transfer" approach proposed by [27]. The adjustment takes into account differences in income levels between two places, all other socioeconomic conditions being similar (ceteris paribus).

$$
V S L_{p}=V S L_{s}\left(\frac{Y_{p}}{Y_{s}}\right)^{\beta}
$$

Here, $Y$ is the Gross Domestic Product GDP per capita (at purchasing power parity PPP prices), with subscripts $p$ and s indicating policy (Skopje) and study (EU-27) locations, respectively. The coefficient $\beta$ is the income elasticity factor, the marginal change in cost for a marginal change in income. In this study, we assumed $\beta$ equals one, although other values have also been suggested in the literature $[27,28]$. Application of (2) to the case of Skopje yields 1.23 million euros (This value would be applied to deaths in year 2012). For all cost adjustments in this work, we assumed $\$ 13,500$ and $\$ 34,500$, respectively, for Skopje and EU-27 GDP per capita (PPP prices), and a purchase power parity exchange of 0.87 euros (2013) to the US dollar (2005). All costs in this study are stated in constant 2013 prices. 
The VSL varies year-to-year based on income growth and choice of discount rate. In this analysis we assumed a real growth rate (excluding inflation) of $2 \%$ per annum, whereas future costs and benefits have been discounted at a rate of $3 \%$ per annum.

Another approach to valuing premature deaths is to calculate the economic value attributed to the number of years lost, or loss of life expectancy, in the exposed population. For this type of assessment, we use the "value of a life year" (VOLY). Empirical values of VOLY have been determined using WTP studies in which respondents to questionnaires assigned monetary values to small gains in life expectancy, typically on the order of a few months, from mortality risk reductions in the context of exposure to ambient pollution. Unlike the VSL literature, only few studies in selected European countries have been carried out to date on the VOLY estimation. Further, these studies lack statistical strength due to the small sample sizes that were used in the analysis. Another frequent criticism in using this metric to value mortality impacts has been the lack of information on how VOLY might vary with age. For small changes in life expectancy, (i.e., on the order of months or at most a few years, such as would be the case of chronic exposure to air pollution) the VOLY has been used, while the VSL is the preferred valuation metric for accidental or immediate (also referred to acute mortality) deaths [29]. As the current population of Skopje ages over time, the mortality damage cost in future years varies depending on YLL and the VOLY. For our analysis, we chose a VOLY of 49,356 euros (2013 prices) in year 2012, calculated using the same benefit-transfer methodology applied to the VSL, and assuming a reference VOLY value of 126,000 euros for EU-27 (adapted from Holland, 2014).

\section{Results}

\subsection{Mortality and Ylls Attributable to Air Pollution in 2012 under Different Scenarios}

At current pollution levels $\left(49 \mu \mathrm{g} / \mathrm{m}^{3}\right)$, the PM attributable mortality is 1199 premature deaths (C195\% 821-1519) in 2012. A hypothetical implementation of the EU limits could have averted an estimated 545 premature deaths, which is equivalent to a $45 \%$ decrease compared to the current situation, while a hypothetical reduction of PM levels to the WHO AQG could have averted an estimated 926 premature deaths (77\% decrease).

Regarding the years of life lost (YLL) by the 1199 estimated premature attributable deaths in 2012, these were estimated at 16,209 YLLs. This number is interpreted as the sum of lost years of life accrued by these individuals as a result of dying before their expected remaining lifetime at the time of death. The YLL per death equals 13.5, and the average loss of life expectancy among adults older than 30 years is 18 days (See Figure S1) - this figure applies to the population alive in year 2012 in this cohort and decreases as the population ages.

Overall, a significant number of YLLs could be prevented by policies that aim to mitigate air pollution. During the first year alone, the avoidable YLLs under Scenario 1 are 306, while the figure increases to 476 for Scenario 2. The life expectancy of the population at the current pollution level is 76.4 years at birth and 16.3 years for individuals older than 65 (See Table 3).

The data listed in the table in columns "Number of deaths" and "Years of life lost" represent the current burden in year 2012 ("Current situation"), as well as the residual burdens under the two specified scenarios. In other words, under Scenario 2 (WHO AQG), there will still be 32.4 thousand deaths and 372 thousand YLL across the population aggregated over a time horizon of 105 years (i.e., the follow-up time until everyone alive in 2012 has died). Life expectancy increases as pollution levels are reduced (top to bottom in column 2). Thus, a shift from the current situation to Scenario 2 increases life expectancy at birth by 2.2 years. Compared to a hypothetical population unexposed to ambient pollution, even at the recommended WHO target there would still be a loss of life expectancy at birth of about one-half year (column 3). The long-term impacts of air pollution can be considered if the data are aggregated for a population alive in 2012 over the mentioned follow up period of 105 years, assuming a constant birth rate (See Figure 1). 
Table 3. Health burdens of the different $\mathrm{PM}_{2.5}$ scenarios, expressed as aggregate impact over a follow-up period of 105 years.

\begin{tabular}{ccccc}
\hline $\begin{array}{c}\text { PM2.5 Ambient } \\
\text { Concentrations }\end{array}$ & $\begin{array}{c}\text { Life Expectancy } \\
\text { (Years) }\end{array}$ & $\begin{array}{c}\text { Loss of Life } \\
\text { Expectancy * (Years) }\end{array}$ & $\begin{array}{c}\text { Number of Deaths } \\
\text { (Thousands) } * *\end{array}$ & $\begin{array}{c}\text { Years of Life Lost } \\
\text { (Thousands) }\end{array}$ \\
\hline Current situation: & 76.4 (at birth) & 2.8 (at birth) & 179.9 & 1813 \\
$49.2 \mu \mathrm{g} / \mathrm{m}^{3}$ & $16.3(65$ years) & $2.1(65$ years) & $(123.2-227.9)$ & $(1177-2413)$ \\
\hline Scenario $1: \mathrm{EU}$ & 77.7 (at birth) & 1.4 (at birth) & 84.8 & 926.5 \\
AQS $\left(25 \mu \mathrm{g} / \mathrm{m}^{3}\right)$ & $17.3(65$ years) & $1.1(65$ years) & $(59.7-104.6)$ & $(600.3-1235)$ \\
\hline Scenario $2: \mathrm{WHO}$ & 78.6 (at birth) & 0.6 (at birth) & 32.4 & 372.0 \\
AQG $\left(10 \mu \mathrm{g} / \mathrm{m}^{3}\right)$ & $18.0(65$ years) & $0.5(65$ years) & $(23.2-39.4)$ & $(240.7-496.6)$ \\
\hline
\end{tabular}

* Loss of life expectancy compared to a hypothetical unexposed population (life expectancy $=79.15$ years at birth and 18.45 years at age 65$) * *$ Values in brackets show $95 \%$ confidence intervals of estimates based solely on the RR uncertainty interval indicated in Table 2.

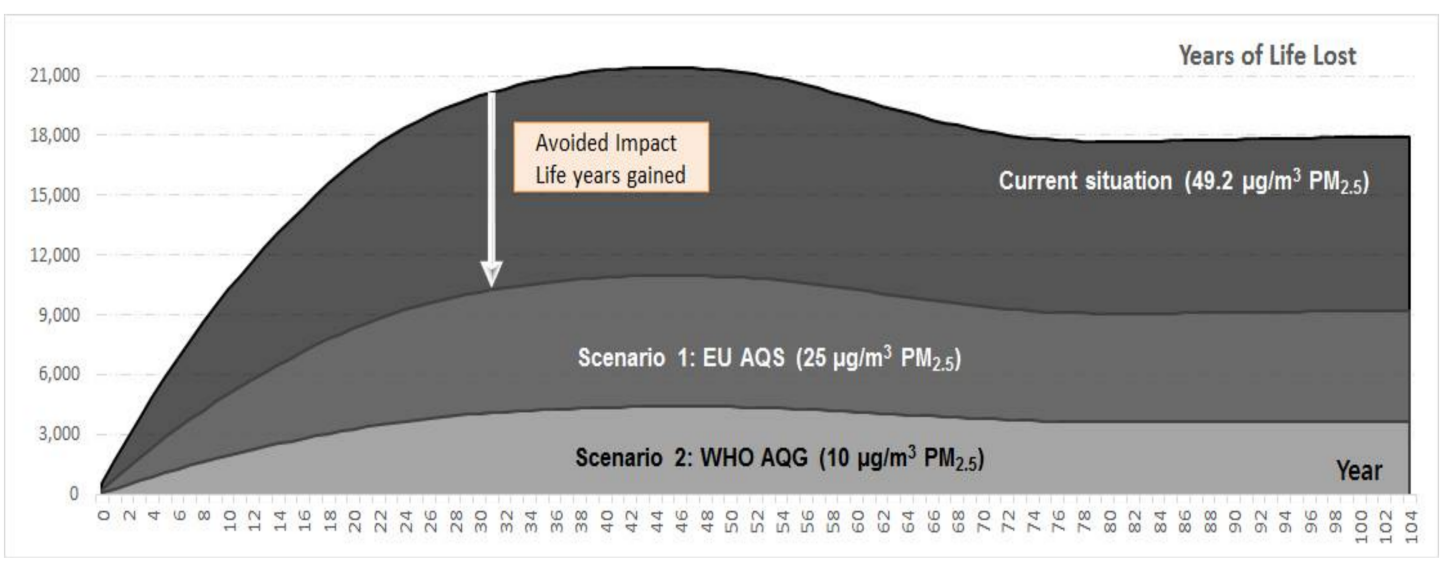

Figure 1. Health burden in terms of YLL and potential benefits under different mitigation scenarios.

\subsection{Morbidity Attributable to Air Pollution in Year 2012 and Avoidable Impacts under Different Mitigation Scenarios}

Morbidity outcomes were calculated for hospital admissions due to cardiovascular and respiratory diseases. The results under different scenarios are summarized in Table 4. Different proportions of the attributable morbidity in 2012 could have been "avoided" in scenarios with lower concentrations of $\mathrm{PM}_{2.5}$. Specifically, $19.9 \%$ of hospital admissions for cardiac disease and $19.6 \%$ for respiratory disease could have been "avoided" by achieving the EU standards; and $50.2 \%$ of hospital admissions for cardiac disease and $49.6 \%$ for respiratory disease could have been "avoided" by attaining the WHO air quality guidelines.

Table 4. Morbidity outcomes under different $\mathrm{PM}_{2.5}$ scenarios in year 2012.

\begin{tabular}{cccc}
\hline Morbidity & Current Situation & $\begin{array}{c}\text { Scenario 1 EU Limits } \\
\mathbf{( 9 5 \% ~ C I )}\end{array}$ & $\begin{array}{c}\text { Scenario 2 WHO AQG } \\
\mathbf{( 9 5 \% ~ C I ) ~}\end{array}$ \\
\hline $\begin{array}{c}\text { Hospital admission for } \\
\text { cardiovascular diseases }\end{array}$ & 547 & 438 & 272 \\
\hline $\begin{array}{c}\text { Hospital admissions for } \\
\text { respiratory disease }\end{array}$ & $(104-977)$ & $(83-784)$ & $(51-490)$ \\
\hline
\end{tabular}

\subsection{Economic Benefits of Reduced Premature Mortality}

The social cost for the estimated premature mortality attributable to $\mathrm{PM}_{2.5}$ in the year 2012 in Skopje was between 570 M€ (VOLY metric) and 1470 M€ (VSL metric). Significant cost savings at the social level could be attained through air pollution abatement. Assuming a long-term real income 
growth of $2 \%$ and a $3 \%$ discount rate, the mean annual benefit of the mortality reduction achieved through Scenario 1 is between $251 \mathrm{M} €$ (using the VOLY metric) and $697 \mathrm{M} €$ (VSL metric). For scenario 2, the annual accrued benefit would be between $407 \mathrm{M} €$ (using the VOLY metric) and $1081 \mathrm{M} €$ (VSL metric). The health benefits and social costs of the two alternative scenarios can be visualized in a distribution across the population by distinguishing the present generation (population alive in 2012) versus future generations (up to 105 years into the future). Over a follow-up period of 105 years of the population alive in Skopje in the year 2012, and also accounting for future generations, the accumulated benefits of avoided premature mortality due to air pollution are substantial (see Figures 2 and 3). With a VOLY valuation, the cumulative benefits would be of 26.3 billion $€$ ( 2013 prices) under Scenario 1 and 42.7 billion $€$ under Scenario 2. With VSL valuation, the benefits would be 73 billion $€$ (2013 prices) under Scenario 1 and 114 billion $€$ under Scenario 2.

\section{Benefits of $\mathrm{PM}_{2.5}$ emission reductions \\ (Scenario 1: EU AQS $25 \mu \mathrm{g} / \mathrm{m}^{3}$ )}

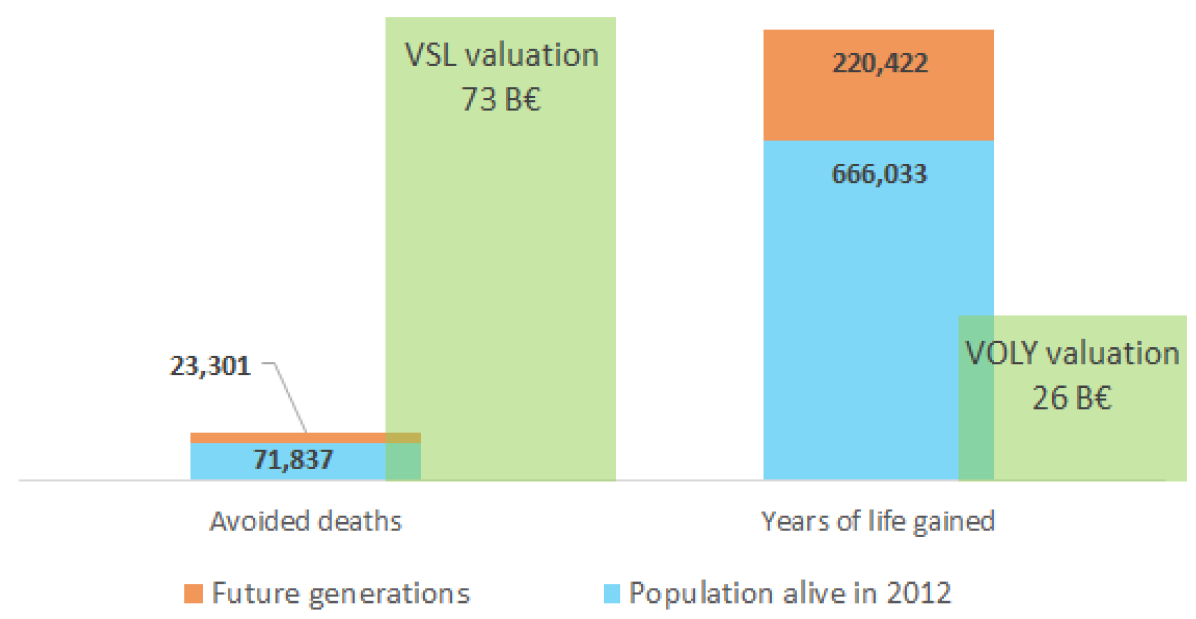

Figure 2. Scenario 1: cumulative mortality benefit of $\mathrm{PM}_{2.5}$ emission reductions for the city of Skopje aggregated over a follow up period of 105 years.

\section{Benefits of $\mathrm{PM}_{2.5}$ emission reductions \\ (Scenario 2: WHO AQG $10 \mu \mathrm{g} / \mathrm{m}^{3}$ )}

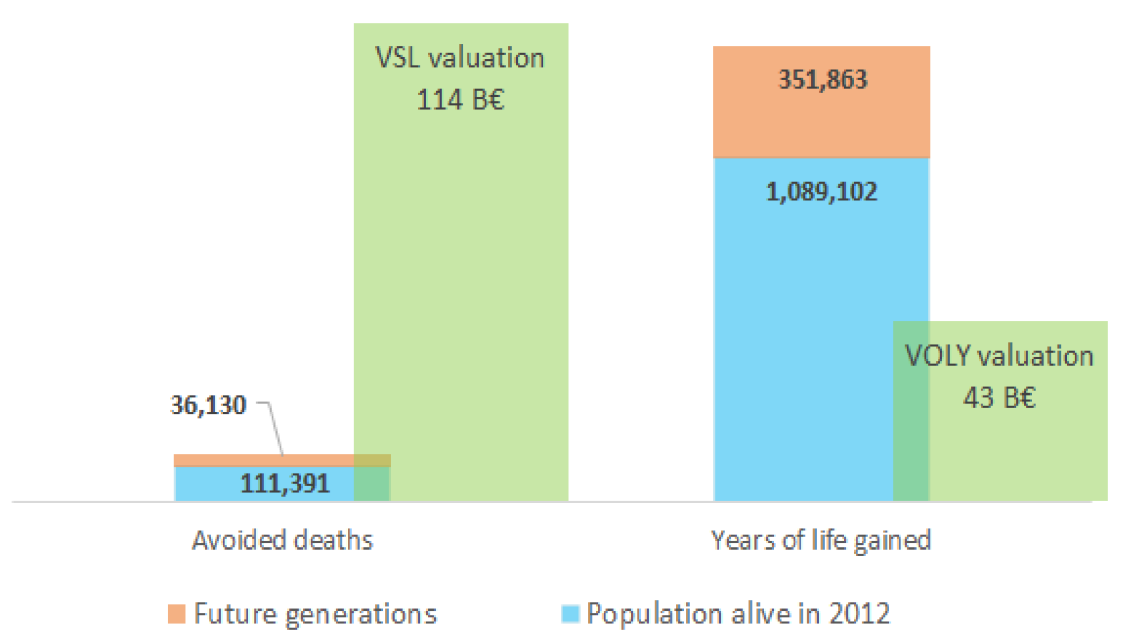

Figure 3. Scenario 2: Cumulative mortality benefit of $\mathrm{PM}_{2.5}$ emission reductions for the city of Skopje aggregated over a follow up period of 105 years. 


\section{Discussion}

In the year 2012, at current pollution levels $\left(49 \mu \mathrm{g} / \mathrm{m}^{3}\right)$, we estimated that $\mathrm{PM}_{2.5}$ may have caused an estimated attributable mortality of 1199 deaths, as well as 547 hospital admissions for cardiovascular diseases and 937 hospital admissions for respiratory diseases, with a social cost of between $570 \mathrm{M} €$ and $1470 \mathrm{M} €$. Of all these estimated impacts, a hypothetical implementation of the EU limits could have averted an estimated $45 \%$ of premature deaths, about $20 \%$ of hospital admissions both for cardiovascular and respiratory diseases, and yielded social cost savings of between $251 \mathrm{M} €$ and $697 \mathrm{M€}$. A hypothetical further reduction of PM levels to the WHO AQG could have averted an estimated $77 \%$ of premature deaths, about $50 \%$ of hospital admissions for both cardiac disease and respiratory disease, and yielded social cost savings of between $407 \mathrm{M} €$ and $1081 \mathrm{M} €$. Consistently, the accumulated benefits of avoided premature mortality over the long term due to air pollution would be substantial.

Both the health impact assessment and the health economic valuation of air pollution in Skopje are generally higher than previous results for MKD as a whole. The World Bank [30] estimated that approximately 1350 premature deaths were attributable to inhalable particulate matter in MKD in 2011, with an economic cost of $€ 253$ million annually or 3.2\% of the national GDP. Our results for Skopje in terms of attributable mortality would thus represent almost $90 \%$ of the World Bank estimate for the whole country, of which only about a quarter of the population lives in the capital. Although that study did not show the downscaled mortality burden to the urban level, it did show the disaggregated health-related economic burden, including VSL-based mortality cost, of air pollution to be heavily concentrated in Skopje (45\% of the total). A related paper by the same team [31] elaborated further on the methodology of the World Bank study. Their RR functions, taken from an older review [16] are for cause-specific endpoints (long-term cardiopulmonary and lung mortality) compared to the all-cause natural mortality RR that we used [14]. Further, we assume no counterfactual for the current situation, but there is a recommended cutoff $\left(7.5 \mu \mathrm{g} / \mathrm{m}^{3}\right.$ for $\left.\mathrm{PM}_{2.5}\right)$ in the mentioned review. These factors would suggest a smaller difference between the World Bank estimates and ours than expected on the basis of population and measured pollution concentrations alone.

Another study [32] provides an estimate in 2013 of 3360 deaths attributable to $\mathrm{PM}_{2.5}$ (annual mean $30.4 \mu \mathrm{g} / \mathrm{m}^{3}$ ) for the whole country. Adjusting for the difference in share of the population $30+\mathrm{in}$ Skopje and nationally (62.4\% and 59\% respectively), as well as for the differences in exposure (urban in Skopje vs. a mix of urban and rural nationally), their adjusted premature mortality estimate is within $15 \%$ of our result.

Our study has a number of limitations. We have assumed a log-linear function between exposure and response to ambient pollution, so health effects would be the same for incremental ranges of pollution at different levels. For the relatively high exposures experienced in Skopje, this is likely to result in an over-estimation of the burden, as well as of the health co-benefits associated with reduced pollution. On the other hand, however, our results should be interpreted as conservative. For instance, some relevant pollutants were excluded from the analysis (e.g., ozone and $\mathrm{NO}_{2}$ ), although their relative contribution to health morbidity and mortality is likely to be relatively small compared with PM [14]. Furthermore, some important nonfatal health endpoints such as aggravation of asthma and other chronic respiratory diseases, which may in turn impact a person's ability to work or engage in routine daily activities, were excluded, but could represent significant additional health and economic burdens on the population and social services. In past European studies, morbidity costs accounted for 10 to $15 \%$ of the total health cost when mortality was valued using VSL [12].

The data availability for our study was not optimal, with a very low coverage of measurements for most stations in 2011, and to a lesser extent in 2013. These periods of non-functionality of the measuring stations were officially noted at the yearly reports of the Macedonian Ministry of the Environment, hinting at the urgent need for the air quality monitoring system in Skopje to be strengthened, particularly the geographical and time series coverage of measurements, as well as the availability of adequate human and physical resources for monitoring. 
Notwithstanding these limitations, both our results and previous ones highlight the urgency of reducing the exposure to particulate matter in urban settings in MKD. The World Bank [30] provided policy advice for such reduction tailored to the emissions profile of the country, targeting pollution abatement in the industrial sector, a quick transition from the current lignite-based energy generation to a gas-based one, a mix of sustainable transportation policies, efficient residential stoves and boilers, and an adequate system of incentives for compliance at all levels. These are aligned with the Macedonian Government EU-backed regulatory efforts towards compliance with the EU environmental acquis, making the issue of implementation the most pressing concern. Such implementation is likely to be more sustainable and effective if it is supported by adequate multi-level governance structures and inclusive policy processes [33].

\section{Conclusions}

Inhalable particulate matter causes significant mortality and illness in Skopje. The average life expectancy of the residents of Skopje is being reduced by 2 to 3 years through a largely preventable environmental factor like anthropogenic air pollution. It also entails a sizeable welfare cost to society. While there is no safe level of PM, any decrease in concentrations will benefit health in Skopje by decreasing premature mortality and morbidity, and related economic costs. The attainment of the European Union standards for PM can provide substantial health and economic benefits, but the attainment of WHO air quality guidelines levels can provide further benefits and should eventually constitute a policy goal. Our results underscore the urgency of implementation of measures to reduce emissions and, ultimately, exposure.

Even a limited assessment like the one featured in this work can provide useful evidence for policymaking. This is currently very relevant, as MKD continues to align its regulations with the EU acquis [34] on environmental issues and is in the process of implementing a National Environmental Health Action Plan to tackle the main environmental concerns in the country. More research and local evaluations on the health and economic impacts of urban air pollution are needed, particularly in EU accession countries and other neighboring countries in which the local evidence base on this topic is scarce.

Supplementary Materials: The following are available online at http:/ / www.mdpi.com/1660-4601/15/4/626/s1. Figure S1-Time trend of mid-year population stratified by age under current conditions; Figure S2 - Costs of $\mathrm{PM}_{2.5}$ concentrations and mitigation scenarios for the city of Skopje; Figure S3-Cumulative mortality cost based on YLL for current pollution level.

Acknowledgments: The research leading to these results has received funding from the European Community's Seventh Framework Programme under (Grant Agreement No. 308497) (Project RAMSES). This paper reflects the authors' views. The European Commission is not liable for any use that may be made of the information contained therein. We gratefully acknowledge the continued support from the Federal Ministry for the Environment, Nature Conservation, Building, and Nuclear Safety (Bundesministerium für Umwelt, Naturschutz, Bau und Reaktorsicherheit) for our activities in this area, including research. We also thank Margarita Spasenovska, from the WHO Country Office in MKD, for her on-site coordination and support in data collection.

Author Contributions: G.S.M. and P.M. directed and coordinated the study, D.C. conducted the air pollution data cleaning and concentrations' statistical analysis. J.V.S. and P.M. carried out the epidemiological calculations. J.V.S. and G.S.M. carried out the economic calculations. V.K. and M.K. provided valuable inputs. All authors read and approved the final manuscript.

Conflicts of Interest: The authors declare no conflict of interest.

\section{References}

1. Brunekreef, B.; Holgate, S.T. Air pollution and health. Lancet 2002, 360, 1233-1242. [CrossRef]

2. World Health Organization (WHO). Ambient Air Pollution. A Global Assessment of Exposure and Burden of Disease; World Health Organization: Geneva, Switzerland, 2016.

3. Correia, A.W.; Pope, C.A.; Dockery, D.W.; Wang, Y.; Ezzati, M.; Dominici, F. The Effect of Air Pollution Control on Life Expectancy in the United States: An Analysis of 545 US counties for the period 2000 to 2007. Epidemiology 2013, 24, 23-31. [CrossRef] [PubMed] 
4. WHO Regional Office for Europe. Review of Evidence on Health Aspects of Air Pollution—REVIHAAP Project Technical Report; World Health Organization, Regional Office for Europe: Copenhagen, Denmark, 2013.

5. Naumovski, K.; Krstev, B.; Basovski, G.; Todeva, T.; Krstev, A. Conditions and impacts on industrial processes and atmospheric approaches of air pollution in the Skopje and Polog region. Nat. Resour. Technol. 2017, $11,75-82$.

6. Kochubovski, M.; Kendrovski, V. Monitoring of the Ambient Air Quality $\left(\mathrm{PM}_{10}\right)$ in Skopje and Evaluation of the Health Effects in 2010. J. Environ. Prot. Ecol. 2012, 13, 789-796.

7. Kovacevik, B.; Wagner, A.; Boman, J.; Laursen, J.; Pettersson, B. Elemental composition of fine particulate matter $\left(\mathrm{PM}_{2.5}\right)$ in Skopje, FYR of Macedonia. X-ray Spectrom. 2011, 40, 280-288. [CrossRef]

8. Anttila, P.; Stefanovska, A.; Nestorovska-Krsteska, A.; Grozdanovski, L.; Atanasov, I.; Golubov, N.; Walden, J. Characterisation of extreme air pollution episodes in an urban valley in the Balkan Peninsula. Air Qual. Atmos. Health 2016, 9, 129-141. [CrossRef]

9. Kendrovski, V.T. The impact of ambient temperature on mortality among the urban population in Skopje, Macedonia during the period 1996-2000. BMC Public Health 2006, 6, 44. [CrossRef] [PubMed]

10. Kendrovski, V.; Spasenovska, M.; Menne, B. The public health impacts of climate change in the former Yugoslav Republic of Macedonia. Int. J. Environ. Res. Public Health 2014, 11, 5975-5988. [CrossRef] [PubMed]

11. Stafilov, T.; Bojkovska, T.; Hirao, M. Air pollution monitoring system in the Republic of Macedonia. J. Environ. Prot. Ecol. 2003, 4, 518-524.

12. Holland, M. Cost Benefit Analysis of Final Policy Scenarios for the EU Clean Air Package; The International Institute for Applied Systems Analysis: Laxemburg, Austria, 2014.

13. World Health Organization (WHO). Air Quality Guidelines for Particulate Matter, Ozone, Nitrogen Dioxide and Sulfur Dioxide. Global Update 2005; Summary of Risk Assessment; World Health Organization: Geneva, Switzerland, 2006.

14. World Health Organization (WHO). Health Risks of Air Pollution in Europe-HRAPIE Project Recommendations for Concentration-Response Functions for Cost-Benefit Analysis of Particulate Matter, Ozone and Nitrogen Dioxide; World Health Organization Regional Office for Europe: Copenhagen, Denmark, 2013.

15. Martuzzi, M.; Mitis, F.; Iavarone, I.; Serinelli, M. Health Impact of Ozone in 13 Italian Cities; Europe PMC: London, UK, 2013.

16. Ostro, B. Outdoor Air Pollution-Assessing the environmental burden of disease at national and local levels. In Environmental Burden of Disease Series; World Health Organization: Geneva, Switzerland, 2004.

17. Air Quality Assessment Report: Air Quality Assessment of Sulphur Dioxide, Nitrogen Dioxide, Nitrogen Oxides, Carbon Monoxide, Particulate Matter, Ozone, Lead, Arsenic, Nickel and Cadmium Concentrations in Republic of Macedonia. Available online: http://airquality.moepp.gov.mk/airquality/wp-content/ uploads/2012/03/Preliminary-assessment-report_200412_SL-FINAL.pdf (accessed on 26 January 2018).

18. State Statistical Office of Macedonia. Statistical Review: Population and Social Statistics; State Statistical Office of Macedonia: Skopje, Republic of Macedonia, 2016.

19. State Statistical Office of Macedonia. Statistical Review: Population and Social Statistics; State Statistical Office of Macedonia: Skopje, Republic of Macedonia, 2013.

20. Hoek, G.; Krishnan, R.M.; Beelen, R.; Peters, A.; Ostro, B.; Brunekreef, B.; Kaufman, J.D. Long-term air pollution exposure and cardio-respiratory mortality: A review. Environ. Health 2013, 12, 43. [CrossRef] [PubMed]

21. WHO Regional Office for Europe. AirQ+: Software Tool for Health Risk Assessment of Air Pollution. Available online: http:/ / www.euro.who.int/en/health-topics/environment-and-health/air-quality/activities/airqsoftware-tool-for-health-risk-assessment-of-air-pollution (accessed on 26 January 2018).

22. Mudu, P.; Gapp, C.; Dunbar, M. WHO AirQ+ tool: Methodologies to calculate the impacts of air pollution on health. In Proceedings of the 5th WeBIOPATR Workshop \& Conference, Belgrade, Serbia, 14-16 October 2016; pp. 196-199.

23. European Union (EC). Directive 2008/50/EC of the European Parliament and of the Council of 21 May 2008 on Ambient Air Quality and Cleaner Air for Europe; European Commission: Brussels, Belgium, 2008.

24. HEATCO Developing Harmonized European Approaches for Transport Costing and Project Assessment-Deliverable 5: Proposal for Harmonized Guidelines. Available online: http://heatco.ier. uni-stuttgart.de/HEATCO_D5.pdf (accessed on 1 February 2006). 
25. Chanel, O.; Luchini, S. Monetary Values for Air Pollution Risk of Death: A Contingent Valuation Survey; Updated Mimeo of Working Paper \# 2008-5; Working Papers Halshs-00272776; HAL: Marseille, France, 2012. Available online: https:/ / halshs.archives-ouvertes.fr/halshs-00272776 (accessed on 26 February 2006).

26. Methodology for the Cost-Benefit Analysis for CAFE: Volume 3-Uncertainty in the CAFE CBA. Available online: http:/ / ec.europa.eu/environment/archives/cafe/ (accessed on 26 January 2018).

27. The Organisation for Economic Co-operation and Development (OECD). Valuing Mortality Risk Reductions in Regulatory Analysis of Environmental, Health and Transport Policies: Policy Implications; OECD: Paris, France, 2011.

28. Hammitt, J.K.; Robinson, L.A. The Income Elasticity of the Value per Statistical Life: Transferring Estimates between High and Low Income Populations. J. Benefit-Cost Anal. 2011, 2, 1-29. [CrossRef]

29. Rabl, A.; Spadaro, J.; Holland, M. How Much Is Clean Air Worth?: Calculating the Benefits of Pollution Control; Cambridge Univ. Press: Cambridge, UK, 2014.

30. The World Bank. FYR Macedonia: Green Growth Country Assessment; The World Bank: Washington, DC, USA, 2014.

31. Meisner, C.; Gjorgjev, D.; Tozija, F. Estimating health impacts and economic costs of air pollution in the Republic of Macedonia. South East. Eur. J. Public Health 2015, 4. [CrossRef]

32. European Environment Agency (EEA). Air Quality in Europe-2016 Report; EEA: Copenhagen, Denmark, 2016.

33. Donevska, N. Trade-offs in sustainable urban development: The case of Skopje. J. Environ. Stud. Sci. 2017, 7, 152-159. [CrossRef]

34. European Environment Agency (EEA). The Former Yugoslav Republic of Macedonia Country Briefing-The European Environment-State and Outlook 2015; EEA: Copenhagen, Denmark, 2015.

(C) 2018 by the authors. Licensee MDPI, Basel, Switzerland. This article is an open access article distributed under the terms and conditions of the Creative Commons Attribution (CC BY) license (http://creativecommons.org/licenses/by/4.0/). 